\title{
Diferenciais de salários dentro do Poder Executivo Brasileiro:
}

\section{uma análise de cluster}

\section{Tailiny Ventura 1}

\section{Marco Antonio Ribas Cavalieri 2}

1 Universidade Federal de Minas Gerais / Centro de Desenvolvimento e Planejamento Regional, Belo Horizonte / MG - Brasil

2 Universidade Federal do Paraná / Pós-Graduação em Desenvolvimento Econômico e Pós-graduação em Ciência Política,

Curitiba / PR - Brasil

\begin{abstract}
O objetivo principal do presente trabalho é verificar como evoluiu o padrão remuneratório das diferentes carreiras com nível superior dentro do Poder Executivo Federal ao longo do período de 1998 a 2015. A justificativa para se estudar esses diferenciais salariais é que, nos últimos anos, se verificou um aumento substancial dos salários do funcionalismo público brasileiro. No entanto, os resultados obtidos pela técnica de análise de agrupamento sugerem que existe um padrão de maior valorização das carreiras chamadas típicas de Estado, em detrimento de outras. Isso revela um padrão de apreciação de salários dentro do Poder Executivo e, principalmente, um conflito distributivo interno, em que aquelas carreiras mais próximas do poder central e com as características de "típicas de Estado" foram sendo gradativamente beneficiadas, estabelecendo uma grande mudança no padrão remuneratório relativo ao longo do período analisado.
\end{abstract}

Palavras-chave: análise de cluster; salários públicos; Poder Executivo Brasileiro; carreiras de estado.

\section{Diferenciales salariales en el Poder Ejecutivo brasileño: análisis de conglomerados}

El objetivo principal del presente trabajo es verificar cómo ha evolucionado el patrón retributivo de las distintas carreras con educación superior dentro del Poder Ejecutivo federal durante el período de 1998 a 2015. La justificación para estudiar estos diferenciales salariales es que, en los últimos años, se ha verificado un aumento sustancial de los salarios de los funcionarios públicos brasileños. Sin embargo, los resultados obtenidos por la técnica de análisis de conglomerados sugieren que existe un patrón de mayor apreciación de las carreras denominadas típicas del Estado, en detrimento de otras. Esto revela un patrón de apreciación salarial al interior del Poder Ejecutivo $\mathrm{y}$, principalmente, un conflicto distributivo interno, en que las carreras más cercanas al poder central y con las características de "típicas del Estado" fueron paulatinamente beneficiadas, estableciendo un cambio importante en el patrón de remuneración relativa durante el período analizado.

Palabras clave: análisis de conglomerados; salarios públicos; Poder Ejecutivo brasileño; carreras estatales.

\section{Salary discrepancy in the Brazilian executive branch: a cluster analysis}

This paper verifies the evolution of the remuneration pattern of different higher-level careers within the Brazilian federal executive branch from 1998 to 2015. In recent years, the differences in remuneration have substantially increased in the Brazilian civil service. However, the results obtained through cluster analysis suggest a pattern of greater pay raise for "typical state careers" to the detriment of others. This reveals a pattern of salary appreciation within the executive branch and, especially, an internal distributive conflict, in which those careers closer to the central power and with characteristics of "typical state careers" were gradually benefiting, establishing a major change in the relative remuneration pattern among different careers over the studied period.

Keywords: cluster analysis; civil servants salaries; Brazilian federal executive branch; state careers. 


\section{AGRADECIMENTOS}

Esta pesquisa conta com o apoio financeiro do CNPq e da Capes. Os autores agradecem as sugestões e comentários do Prof. Fernando Motta Correia (PPGDE/UFPR). Quaisquer erros remanescentes são de inteira responsabilidade dos autores.

\section{INTRODUÇÃO}

Em um contexto de profunda crise fiscal do Estado, como é a realidade dos últimos anos no Brasil, o debate sobre as remunerações de servidores públicos naturalmente surge como tema relevante. É comum observar, na imprensa e em outras instâncias do debate público, críticas em relação às vantagens das remunerações dos servidores públicos em comparação com os ganhos dos trabalhadores do setor privado. Em trabalhos acadêmicos, quando se trata de remunerações no serviço público, o tema principal é recorrentemente a desigualdade de remunerações públicas versus privadas (Barbosa \& Souza, 2012; Marconi, 2001, 2014; Moriconi, Moura, Marconi \& Arvate, 2009; Souza \& Medeiros, 2013; Vaz \& Hoffmann, 2007). Já o diferencial de salários dentro do próprio setor público é tema mais raro na literatura especializada.

Como apontado, geralmente os trabalhos acadêmicos sobre a diferença das remunerações dos setores público e privado concluem no sentido da vantagem dos trabalhadores daquele setor em relação aos desse último. Tal fenômeno, como afirmam Barbosa e Souza (2012), é algo comum não somente no Brasil, mas em diversos países. Esses mesmos autores, analisando o período entre 1995 e 2011, além de constatarem a vantagem das remunerações do setor público em relação aos ganhos dos trabalhadores do setor privado no Brasil, apontam que no intervalo de tempo analisado esse diferencial ainda aumentou. Em outros trabalhos, como, por exemplo, em Marconi (2014) e em Vaz e Hoffmann (2007) são apresentadas conclusões no mesmo sentido. Já Moriconi (2007) mostra que não existe somente uma significativa diferença salarial entre os setores privado e público, mas há também grande desigualdade dentro do próprio setor público.

O tema do presente artigo é, portanto, o diferencial de salários dentro do setor público, mais especificamente entre carreiras de nível superior do Executivo Federal. O objetivo é mostrar como evoluíram as remunerações dessas diferentes carreiras ao longo do período de 1998 a 2015. Especialmente, são mostrados os movimentos de diferenciação remuneratória entre o segundo mandato presidencial de Fernando Henrique Cardoso, o primeiro e o segundo mandatos de Luís Inácio Lula da Silva e o primeiro mandato de Dilma Vana Rousseff. Como inovação principal, além da análise descritiva dos dados sobre remunerações iniciais e finais das diferentes carreiras corrigidos pela inflação, o trabalho aplica uma análise de agrupamento dos salários para estudar as mudanças de padrão remuneratório relativo entre as carreiras, procurando encontrar um padrão de alterações relativas entre conjuntos de remunerações semelhantes.

A escolha pelo Poder Executivo se deu em razão do processo decisório sobre as remunerações ser feita principalmente, nesse caso, por apenas um poder. Uma vez identificado o padrão, é possível apontar no sentido da existência de um sentido no processo decisório, o que ultrapassaria as fronteiras de gestões diferentes à frente do Executivo Federal. Quanto às carreiras de nível superior, procurou-se estudar um grupo homogêneo, uma vez que o nível educacional não somente é variável fundamental determinante das remunerações no setor público, tanto quanto em geral no setor privado e no mundo todo. É claro que, como a base de dados para esse trabalho é inédita e foi constituída pelos autores, o recorte também se deu em razão das limitações de informações homogêneas para os diferentes poderes da União. 
A motivação para esse trabalho reside no fato de que não somente existe uma luta entre a tecnoburocracia estatal e o setor privado pela apropriação de excedente na forma de remunerações, assim como existe igualmente uma luta interna no setor público, na qual as diferentes categorias disputam as disponibilidades orçamentárias para apropriá-las na forma de vencimentos e de outras vantagens. Além disso, observa-se que há uma dinâmica de barganha dentro do setor público em que as carreiras mais bem remuneradas vão servir de parâmetro para as negociações salariais das categorias de remuneração mais baixa. Portanto, saber como evoluíram as diferenças remuneratórias dentro do setor público pode servir de indicativo para quais serão os padrões remuneratórios que servirão de base para a luta das categorias com menor remuneração. Além de sugerir a existência desse embate remuneratório ao longo do tempo.

São dois os resultados principais. Primeiro, observa-se na evolução do valor real das remunerações das carreiras ao longo do tempo um padrão conjunto chamado no presente estudo de "queda-aumento-queda", correspondente aos períodos dos chefes do Executivo Fernando Henrique Cardoso, Luís Inácio Lula da Silva e Dilma Vana Rousseff. As evoluções do valor real das remunerações de algumas carreiras escapam a esse padrão, mas, em linhas gerais, essa sequência traduz o histórico do valor real das carreiras estudadas.

Em segundo lugar, já derivado da análise de cluster, foi possível mostrar um progressivo ajuste das carreiras analisadas em diferentes grupos remuneratórios, apresentando como as carreiras de nível superior do Executivo Federal foram formando um padrão em grupos estatisticamente distintos de padrões de remuneração. Esses grupos mudaram durante o período analisado, mostrando como determinadas carreiras foram conquistando padrões de remuneração mais altos, sempre aproximando-se das carreiras mais bem remuneradas do Executivo Federal. Um resultado interessante da análise de cluster, nesse sentido, é como algumas carreiras - por exemplo, de auditoria e de gestão - conquistaram um padrão de remuneração que no início do período era apenas ocupado pela carreira de delegado da Polícia Federal.

No que segue, portanto, a apresentação da pesquisa se faz da seguinte maneira. A próxima seção analisa a literatura sobre fatores determinantes dos salários no setor público. A terceira seção apresenta e discute sinteticamente a ocorrência do referido padrão "queda-aumento-queda". Finalmente, a quarta seção mostra a análise de agrupamento, apresentando brevemente sua metodologia, seguida dos resultados e comentários sobre os principais padrões que eles sugerem, e o texto se encerra com as conclusões levantadas

\section{DETERMINANTES DOS SALÁRIOS NO SETOR PÚBLICO: A NEGOCIAÇÃO SALARIAL E OUTROS FATORES}

É razoável admitir que a determinação do nível salarial dentro da administração pública possua forte componente orientado pelas forças políticas dentro do próprio setor público. Entre elas se encontram o governo, respondendo a uma variedade de pressões para a efetivação de diferentes políticas públicas, e a classe dos servidores públicos, dividida em várias categorias. Obviamente, a arrecadação e a conjuntura econômica são fatores cruciais, mas a dinâmica política das negociações que envolvem esses segmentos citados forma um outro lado desse fenômeno. É por isso que, segundo Souza (2005), a determinação dos salários dos servidores públicos pode ser estudada - ou analisada - sob uma ótica de "economia política". Esta envolve, é claro, os fatores puramente econômicos, embora possua um claro sentido de disputa distributiva que depende das relações de poder, e por isso políticas, entre Governo e diferentes categorias de servidores públicos. 
A negociação salarial no setor público deve ser considerada, na visão de Summers (1974), como parte de um processo governamental amplo. Dessa forma, a negociação coletiva deve ser avaliada como resultado de um processo político. Na visão típica da ciência política pluralista norte-americana, a chamada classe tecnoburocrata ${ }^{1}$ soma-se a outros grupos de interesse que disputam fatias da renda nacional e, tratando-se do setor público, em específico, da arrecadação pública. O argumento do autor, então, é que os mais diversos grupos que auferem renda a partir do Governo vão lutar por maior alocação da receita governamental em seus setores. Por exemplo, os servidores disputam o orçamento com fornecedores do Governo, com grupos políticos que têm acesso a fundos específicos - sindicatos, partidos políticos, organizações não governamentais - e com a classe política.

Nessa perspectiva, a classe tecnoburocrata possui o que Bresser-Pereira (1981) caracteriza por "vocação para o poder", a qual é refletida no controle e na administração da produção como um todo. Com base nisso, essa classe disputa espaços de poder, e, sobretudo, remuneração, utilizando como barganha espaços de utilização de seu conhecimento intelectual e atuação funcional. Em tese, quanto maior a organização e quanto mais poder um funcionário burocrata possui, mais elevada será sua posição dentro da hierarquia da organização. Nesse sentido, é possível apontar que maior será sua remuneração. Contudo, nem sempre e, na verdade, quase nunca, a tecnoburocracia vai atuar em conjunto por aumentos lineares entre todas as categorias. A atuação conjunta é um equilíbrio instável, pois para algumas categorias é bem mais fácil impor perdas tanto para os agentes políticos, como para os usuários dos serviços públicos. ${ }^{2}$ Sendo, inclusive, razoável supor que as perdas para os agentes políticos são mais sensíveis do que para o público em geral. Os agentes políticos podem responder mais diretamente, ou seja, com menos mediações, às suas perdas do que os interesses mais difusos e mais dificilmente identificáveis da sociedade em geral.

Desse modo, algumas funções de Estado poderão assim obter maior apoio para conseguir aumentos remuneratórios do que outras. É possível pensar que aqueles servidores que prestam serviços de forma direta à população - a street-level bureaucracy - terão maior facilidade de conseguir apoio junto ao público em geral. Além disso, Summers (1974) considera a possibilidade de que ocorra a união entre servidores e população (eleitores) em busca de melhores serviços e melhores salários. Todavia, na presente análise, não é exatamente esse aspecto de proximidade com o público que prevalece para maiores sucessos na negociação, em vez disso a posição na hierarquia organizacional e o espaço funcional da categoria - ou seja, em qual função do Estado elas atuam.

Wellington e Winter (1969) ressaltam as vantagens da tecnoburocracia pública em função de seu tamanho para as negociações salariais. As questões políticas envolvidas nas negociações de salários

\footnotetext{
${ }^{1}$ Neste trabalho entende-se a tecnoburocracia como uma classe social, assim como a classe proletária, operária ou trabalhadora, ou como a chamada burguesia ou classe capitalista. A tecnoburocracia surge, definitivamente, no contexto e em consequência da revolução tecnológica provocada pelo Capitalismo. O aumento do conhecimento científico e a necessidade da gestão e da aplicação desse conhecimento é o elemento que provê a base para o processo de ascensão dessa classe social, a tecnoburocracia (Bressser-Pereira, 1972, 2008; Martins, 1997). Mais especificamente, embora a tecnoburocracia não seja somente pública, representada, por exemplo, pelos técnicos presentes nas diferentes atividades econômicas privadas - engenheiros, administradores, profissionais de saúde, operadores do direito, etc. - aqui explora-se a tecnoburocracia presente no setor público. É possível dizer, para detalhar melhor o recorte, que a tecnoburocracia do setor público compreende o funcionalismo, especialmente aquele de alta especialização, diferenciado da classe política - detentores de mandatos eletivos permanentemente submetidos a alguma espécie de controle democrático direto.

${ }^{2}$ No que diz respeito ao objeto do nosso trabalho, é importante notar que em 2004 foi constituída a chamada Mesa Nacional de Negociação Permanente (MNNP), com o objetivo de discutir a questão salarial entre servidores públicos e governo. As discussões na MNNP são realizadas principalmente enfatizando o salário base e os benefícios sociais, no entanto, perpassa aos diversos debates referentes a melhores condições de trabalho, reajustes salariais, de forma a evitar a perda do poder de compra dos servidores, políticas salariais permanentes, reposição de salários para categorias que apresentavam defasagem, valorização dos servidores públicos e qualificação dos mesmos (Ministério do Planejamento Orçamento e Gestão, 2016).
} 
fazem com que os custos deixem de ser apenas econômicos como no setor privado, mas que também existam os custos políticos. Uma movimentação grevista, dado o caráter de bens essenciais oferecidos pelo setor público, além de engendrar pressão por parte dos próprios servidores, acaba desencadeando a pressão por parte da população - outra parte interessada nesse processo. ${ }^{3}$

No que se refere ao tamanho da burocracia pública, o estudo de Ventura (2017) encontra evidências empíricas para o Brasil de que as categorias mais numerosas estão associadas às áreas de funcionalismo público consideradas sociais, como o trabalho em universidades, hospitais, e de apoio técnico e administrativo, possuindo remunerações mais baixas e ocupando menores espaços de poder. Já as carreiras ligadas às áreas de finanças, controle, gestão, auditoria, fiscalização, atuação jurídica e policiais são carreiras em geral menos numerosas e com remunerações elevadas, associadas a maiores ocupações de espaços de poder em função de seu espaço funcional. Dessa forma, é possível pensar que, quanto maior for uma categoria dentro da massa empregada no setor público, maior será sua dificuldade em negociar salários com o governo. E quanto maior o espaço de poder ocupado pelas categorias, maior a facilidade em negociar os salários. ${ }^{4}$

Além do gasto com pessoal e a negociação salarial, existem outros fatores importantes na determinação dos salários públicos que fogem ao escopo dessas variáveis. Ehrenberg (1973) afirma que a essencialidade dos serviços poderia ser um desses fatores influentes no poder de barganha de uma categoria na negociação dos salários. Gregory e Borland (1999), por sua vez, colocam a importância do ambiente institucional para a fixação dos salários públicos. De acordo com os autores, os empregados do setor público podem criar incentivos indiretos para ganhar remunerações acima de um nível considerado eficiente. Os políticos estão interessados em aumentar o número de seus votos (Borjas,1980; Bugarin \& Souza, 2005; Gregory \& Borland, 1999), enquanto os burocratas buscam aumentar a arrecadação em prol de aumentar a parcela da receita que será destinada a eles (Niskanen,1971).

Borjas (1980), em um estudo sobre os diferenciais salariais dentro do setor público federal, constrói um modelo que tem como pressuposto o Estado como maximizador de votos. Entre os fatores explicativos, são consideradas variáveis bastante típicas, tais como as diferenças dos salários dos servidores entre as diferentes "agências" do governo. Em seu modelo, variáveis consolidadas na literatura para nível salarial são consideradas como, por exemplo, a escolaridade, mas em conjunto com variáveis eminentemente políticas. Uma das hipóteses do trabalho é de que os salários pagos aos burocratas refletem não apenas as condições de mercado, mas também o fato de que eles têm o poder de controlar a produção dos órgãos em que trabalham. Com o objetivo de alcançar maior apoio junto à sociedade, o Governo concede salários altos para os servidores, já que estes possuem o poder de alterar a imagem governamental incumbente perante seus eleitores. A burocracia pode dificultar a prestação dos serviços públicos quando recebe baixos salários, bem como melhorar essa prestação quando recebe bons salários. É o princípio negocial utilizado, por exemplo, quando servidores de fiscalização aduaneira ou policiais fazem o que ficou conhecido como "operação tartaruga", dificultando, por exemplo, os desembarques de viajantes e mercadorias em portos e aeroportos.

\footnotetext{
${ }^{3}$ A ideia das greves no setor público direciona-se sempre para angariar pressão da população que utiliza os serviços públicos ofertados por determinada categoria. Ao contrário das greves do setor privado, as do serviço público não implicam cessação de produção e a possibilidade de cessação de lucros. O que elas provocam são prejuízos diretos aos usuários dos serviços públicos, o que, muitas vezes, causa prejuízos mais difusos e de mais difícil identificação e mensuração.

${ }^{4} \mathrm{O}$ estudo de Ventura (2018), a partir de um exercício econométrico, também revela que o quantitativo não se mostra uma variável relevante para explicar os reajustes de salários.
} 
Outra variável considerada por Borjas (1980) é o orçamento do órgão público. Quando este se eleva, os salários tendem a aumentar, o que é bastante razoável do ponto de vista de hipótese do modelo. É natural pensar que em períodos de prosperidade da economia e da arrecadação o Estado eleve os salários de seus servidores. Os diferenciais salariais também são explicados segundo o autor pelos diferentes níveis de poder de cada "agência federal". Dessa forma, os órgãos que possuem maior relevância em relação às suas atividades dentro da estrutura governamental terão uma maior parcela da arrecadação. Portanto, os salários dos servidores que atuam nesses órgãos serão mais elevados.

Bugarin e Souza (2005) e Souza (2005) desenvolvem um modelo de competição eleitoral para o caso específico do Brasil, estudando a determinação dos salários mediante a negociação salarial entre o governo e os servidores considerando dois tipos de negociação. Primeiramente, a negociação do governo com o grupo de servidores como um todo e, num segundo momento, a negociação com dois grupos. O primeiro grupo formado por servidores de carreiras típicas de Estado ${ }^{5}$ e, o segundo, com os demais servidores. Nesse sentido, eles concluem que, para o Brasil, o Estado, no intuito de maximizar sua probabilidade de ganhar as eleições, prefere negociar os salários de forma individual com cada categoria. O Governo, então, concede aumentos diferenciados a cada categoria funcional, privilegiando algumas categorias de servidores em detrimento de outras. Esse comportamento é verificado pelos autores nas duas gestões FHC e no primeiro mandato da gestão Lula. A suposição para esse processo foi que a preferência do Governo está relacionada com o tamanho da categoria e sua homogeneidade em termos ideológicos, o que se reflete em como a categoria age em conjunto, em sua coesão na barganha.

O nível de organização dos diferentes grupos de servidores públicos também deve ser considerado importante na determinação dos salários. Grupos bem estruturados e organizados podem conseguir se unir de uma melhor forma para negociar perante o governo. Marconi (2001) destaca que grupos coesos têm maiores possibilidades de se organizar e conseguir limitar a prestação dos serviços públicos. Adicionalmente, quanto maior for a importância da atividade que a categoria realiza, maior será o poder desses servidores de negociação. Nesse sentido, o poder de barganha de algumas categorias pode ser assumido como um fator fundamental na determinação dos salários. Em tese, policiais e profissionais de saúde, por exemplo, teriam mais facilidade nas negociações.

Em um estudo buscando identificar se todos os servidores públicos são bem remunerados, de modo homogêneo, Moriconi (2007) analisa os salários públicos estaduais. Os resultados revelam que as carreiras consideradas típicas de Estado percebem maiores salários do que aquelas consideradas semelhantes no setor privado. No entanto, para as carreiras não exclusivas, os salários são menores e, nos casos em que os salários das carreiras não exclusivas são superiores aos do setor privado, esse percentual é relativamente baixo, se comparado com o diferencial das carreiras típicas. Verifica-se assim, um padrão de valorização de algumas carreiras ao longo do tempo, também para os servidores públicos estaduais.

\footnotetext{
${ }^{5}$ Não existe na Constituição Federal uma disposição que diz que forma clara quais são as carreiras típicas ou exclusivas de Estado. Apenas no artigo 247, incluído pela Emenda Constitucional no 19/1998 se refere às carreiras exclusivas de Estado: "As leis previstas no inciso III do $₫ 1^{\circ}$ do art. 41 e no $₫ 7 \stackrel{\circ}{ }$ do art.169 estabelecerão critérios e garantias especiais para a perda do cargo pelo servidor público estável que, em decorrência das atribuições de seu cargo efetivo, desenvolva atividades exclusivas de Estado." No Brasil existe o Fonacate, o Fórum Permanente das carreiras típicas de Estado, esse fórum possui um projeto de lei para que tais carreiras sejam definidas, no entanto, ainda não foi aprovado. No presente estudo assumiu-se que as carreiras típicas de Estado são as que exercem atribuições que estão relacionadas à expressão do poder estatal e não possui correspondência no setor privado. De acordo com o Fonacate essas carreiras são relacionadas às atividades de arrecadação, finanças e controle, comércio exterior, defensoria pública, regulação, política monetária, diplomacia, advocacia pública, segurança pública, inteligência de Estado, fiscalização, entre outras.
} 
No recém-exposto, buscou-se, além de fazer breve revisão da literatura, mostrar quais são as variáveis que os analistas de remunerações do setor público levam em consideração. Agora, para entender a evolução das remunerações no período estudado, a próxima seção mostra o comportamento das remunerações de várias categorias de nível superior do Executivo Federal brasileiro, no período de 1998 a 2015.

\section{ANÁLISE DESCRITIVA: A EVOLUÇÃO DAS REMUNERAÇ̃̃ES NO EXECUTIVO DA UNIÃO ENTRE 1998 E 2015}

O estudo analisa um total de 32 carreiras diferentes do Executivo da União. ${ }^{6}$ Contudo, a análise limitou-se às carreiras que exigem ensino superior para entrada. $\mathrm{O}$ objetivo, então, é comparar carreiras com mesmo nível de educação exigido, uma vez que o nível educacional é forte variável na determinação das remunerações tanto no setor público quanto fora dele (Marconi, 2014). Para a maioria dessas carreiras, coletaram-se dados de remunerações a partir do ano de 1998, tomando as séries de dados até $2015 .^{7}$ As carreiras pesquisadas foram agrupadas em cinco áreas de atuação, procurando obter dados de categorias representativas de cada uma dessas grandes áreas do serviço público, do executivo da União. As cinco áreas de atuação em que se separam as carreiras são: (1) educação (mormente superior), (2) gestão e finanças, (3) pesquisa científica e tecnológica, (4) jurídica e, (5) auditoria e fiscalização.

A análise, nesse ponto do trabalho, é eminentemente descritiva, e traz conclusões a partir do exame das tendências observadas. Deseja-se identificar se existe um padrão na evolução das remunerações. Comparam-se os dados para as remunerações iniciais e finais das carreiras, sob a hipótese de que são essas remunerações as principais responsáveis por emitir sinais para o mercado de trabalho, a fim de disputar os melhores profissionais disponíveis. Esses sinais de "preço" são emitidos para o mercado de trabalho, o qual pode ser composto por estudantes de nível superior, profissionais com posições no setor privado e mesmo por aqueles que já ocupam outras carreiras no próprio setor público. Para esses dados, foram construídos gráficos das remunerações brutas deflacionadas, tomando como base o último ano da série, 2015 (as remunerações, portanto, estão plotadas a preços de 2015).

Adicionalmente, são calculados índices para as remunerações tomando como base o ano inicial das séries. ${ }^{8}$ A partir desses gráficos, é possível mostrar a evolução do valor real das remunerações partindo de um mesmo ponto. Enquanto a remuneração bruta deflacionada reflete o sinal repassado para o mercado de trabalho no sentido da captação de profissionais para as diferentes carreiras, os índices calculados a partir da mesma base ignoram o nível absoluto das remunerações para mostrar a manutenção do valor real delas em relação ao ponto inicial. Esses dados dão ideia da manutenção, da valorização ou da desvalorização relativa das remunerações da carreira ao longo do período analisado. Igualmente, mostram o comportamento das remunerações em relação ao previsto na Constituição Federal sobre revisão anual e geral de remunerações, sem distinção de índices (Art. 37, X). Vale dizer

\footnotetext{
${ }^{6}$ Aqui cabe um comentário, os dados usados no trabalho se referem às remunerações de vinte carreiras diferentes. No entanto, essas remunerações refletem os ganhos para 32 cargos diferentes dentro do Poder Executivo Federal, uma vez que dentro da mesma carreira existem cargos diferentes. Carreira é, portanto, uma unidade hierarquizada de cargos públicos afins. Como exemplo, a carreira de gestor público é dividida entre vários tipos de gestores: de políticas públicas, analista de finanças e controle, analista de comércio exterior, analista de planejamento e orçamento. Do mesmo modo, a carreira de professor do magistério superior está dividida entre cargos com titulações acadêmicas diferente: especialização, mestrado, doutorado, por exemplo.

${ }^{7}$ Para algumas carreiras os dados estão disponíveis apenas a partir de 2004, como a para a ABIN e 2006, como o caso das agências reguladoras.

${ }^{8}$ Dessa forma, os índices para as diferentes carreiras sejam iguais a 100 (cem) no ano de início das séries.
} 
que esse é um mandamento constitucional sistematicamente descumprido pelas diferentes esferas de poder, em praticamente todos os entes federativos. ${ }^{9}$ Em cada par de gráficos, os gráficos da esquerda mostram o salário em termos brutos e os da direita em termos relativos.

Finalmente, como a combinação de todos os cargos em um só gráfico os tornaria pouco legíveis, foram escolhidos conjuntos de carreiras para serem demonstrados em conjunto. Adicionalmente, em um artigo com essa extensão, seria impossível apresentar vários gráficos com comparações de muitas carreiras. ${ }^{10}$ Buscou-se, então, mostrar carreiras de áreas diversas, para verificar se há um padrão geral ou se a carreira de determinada área destoa do comportamento geral. Sobretudo, os gráficos foram elaborados juntando-se carreiras típicas e não típicas, para efeitos de comparação. Embora haja uma certa dose de juízo subjetivo na escolha dos gráficos a serem demonstrados, acredita-se que eles servem para apresentar as tendências gerais que são descritas.

\section{GRÁFICO 1 EVOLUÇÃO DOS SALÁRIOS EM VALORES REAIS DE 1998 A 2015. INICIAIS (A) E FINAIS (B)}

(a)

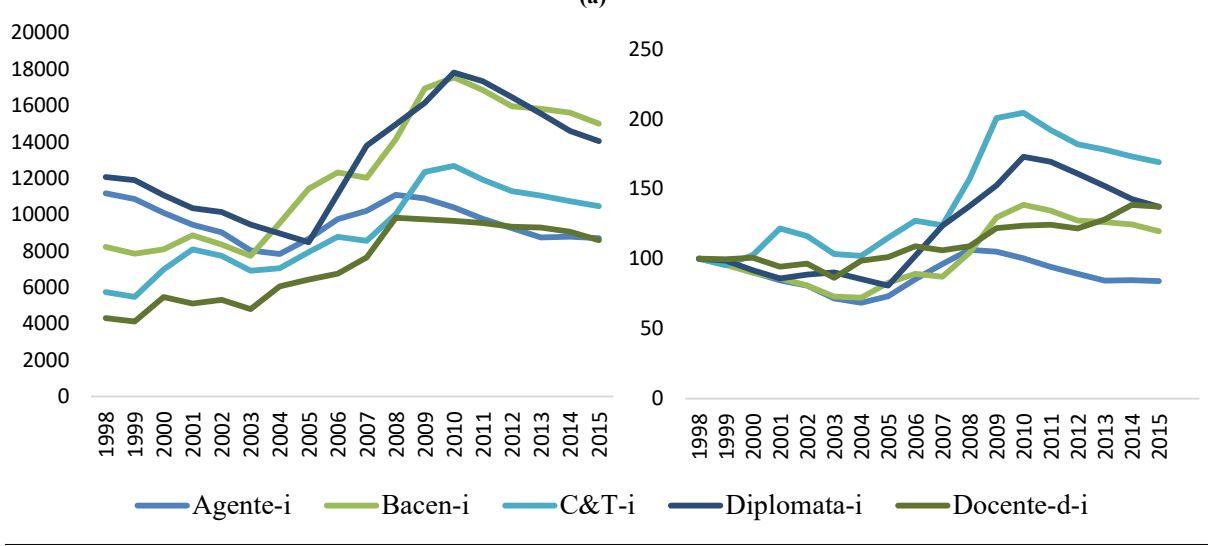

(b)

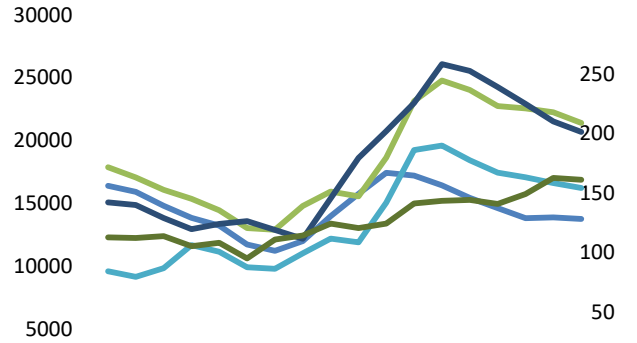

0

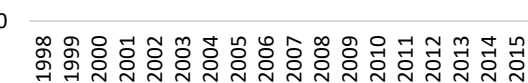

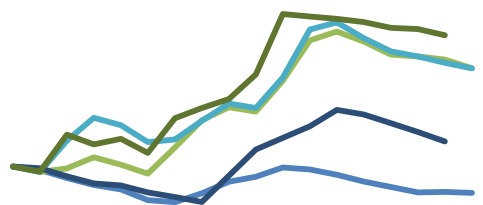

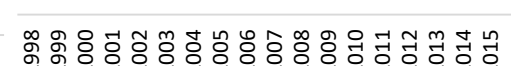

- Agente-f $\longrightarrow$ Bacen-f $\longrightarrow$ C\&T-f $\longrightarrow$ Diplomata-f $\longrightarrow$ Docente-d-f

Fonte: Tabelas de remuneração dos servidores públicos. Elaborado pelos autores.

\footnotetext{
${ }^{9}$ Ver, por exemplo, Douglas, Araújo e Chaves (2014).

${ }^{10}$ Em Ventura (2018) apresentam-se os gráficos completos.
} 
O Gráfico 1 apresenta os salários iniciais (a) e finais (b) para as carreiras de agente da polícia federal, analista do Banco Central do Brasil (Bacen), docente com o título de doutorado, diplomatas, e pesquisadores de ciência e tecnologia com doutorado (doravante pesquisadores em C\&T). No que se refere aos salários iniciais (a), é possível observar que no início do período existia maior igualdade entre as carreiras de docente, diplomata e analista do Bacen, e todas passam por uma queda, e, durante o período as duas últimas passam por aumentos significativos, o que permite que essas carreiras tenham os maiores salários. O pico da valorização das remunerações é visto a partir de 2006. Ao analisar o gráfico da direita, vê-se que em termos relativos, docentes, pesquisadores e analistas do Bacen passaram por maiores aumentos de salários. Os docentes observam a maior valorização, a qual passa de 200\%, em 2008. Porém, ao verificar a remuneração bruta é nítido que apesar dos ganhos relativos, os salários dos diplomatas e dos analistas do Bacen, carreiras típicas de Estado, permanecem significativamente maiores. A valorização dos pesquisadores também é alta, mas em termos brutos ainda há uma diferença relevante. Cabe notar que ambas as carreiras possuem a remuneração adicional pelo título de doutor. De forma geral, todas as carreiras passam por aumento de salários, principalmente no período do Governo Lula, e depois, a partir de 2011, observam queda.

O gráfico (b) mostra os salários finais (teto). O movimento para esses salários é parecido. Inicialmente, todas as carreiras passam por queda em suas remunerações e, depois, passam por grande valorização nos anos do Governo Lula. As carreiras de pesquisador e docente passam por uma valorização abrupta a partir do segundo mandato, no gráfico que apresenta os salários em índice esse movimento pode ser visto de forma bastante clara. Contudo, é necessário ressaltar que o nível dos salários dos diplomatas e analistas do Bacen são maiores e, portanto, permanecem substancialmente maiores ainda que tenha ocorrido grande valorização relativa dos outros salários. Uma hipótese para o aumento apenas da remuneração final é a tentativa de segurar servidores na carreira. No caso em que carreira apresente, por exemplo, aposentadorias precoces ou alta rotatividade. ${ }^{11}$ Contudo, esse trabalho não pode concluir se essa hipótese é verdadeira a partir apenas dos dados apresentados. Mas seria uma boa questão para ser investigada em outra pesquisa.

No caso dos docentes, também cabe destacar que a valorização é significativamente maior no caso dos salários iniciais, o que pode indicar a tentativa de uma política de atratividade, especialmente de doutores, para carreira. Embora, é claro, outras hipóteses possam ser formuladas para explicar essa diferença. Outra hipótese pode passar, por exemplo, pelo quantitativo de servidores em cada nível de carreira e seu fator de desconto intertemporal na percepção da renda - em geral os indivíduos preferem renda no presente ao invés de renda esperada no futuro. Assim, caso a maior parte da categoria esteja nos níveis iniciais, na barganha com o governo, uma proposta que valoriza mais os níveis iniciais têm maior possibilidade de ser aceita pelos servidores do que uma proposta que valoriza os níveis finais - infelizmente os quantitativos de servidores em cada nível da carreira não estão disponíveis nos instrumentos de transparência do executivo federal. A respeito dos salários finais, a lógica entre carreira típica de Estado versus carreira que exige doutoramento não se inverte.

\footnotetext{
${ }^{11}$ Há a possibilidade de que a reforma dada pela emenda constitucional 19/1998 tenha incentivado servidores a sair da carreira precocemente - antes de atingir o último nível - o que ensejaria um contra movimento do Governo na valorização daqueles que decidissem permanecer até o último nível. Contudo, essa é apenas uma hipótese que poderia ser testada com dados detalhados sobre essa carreira em específico
} 


\section{GRÁFICO 2 EVOLUÇÃO DOS SALÁRIOS EM VALORES REAIS DE 1998 A 2015. INICIAIS (A) E FINAIS (B)}

(a)

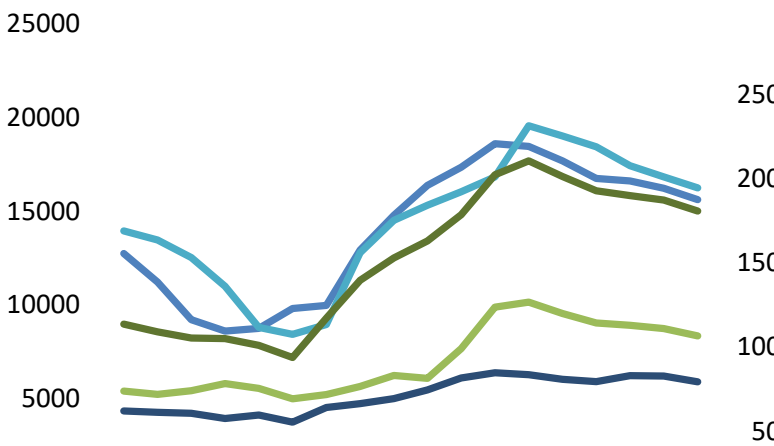

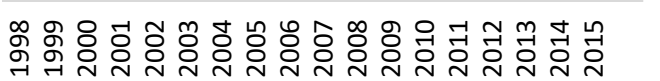

AuditorP-i

C\&T-m-i

Defensor-i

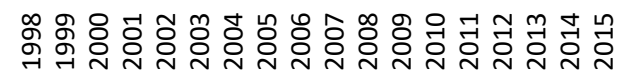

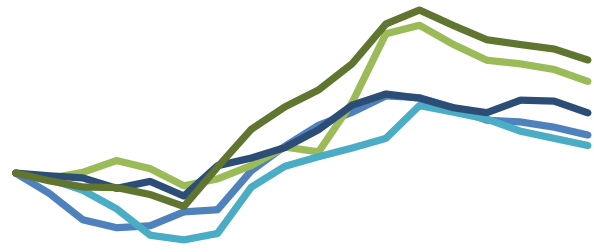

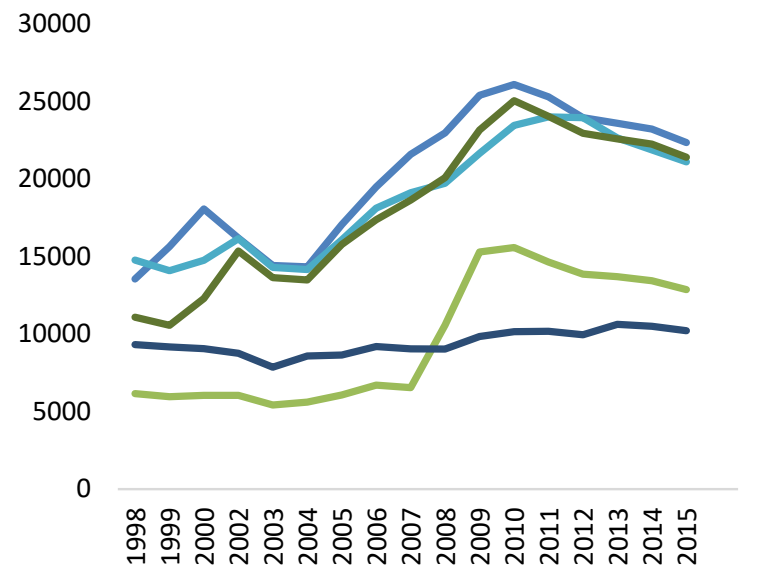

(b)

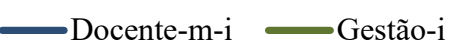

300

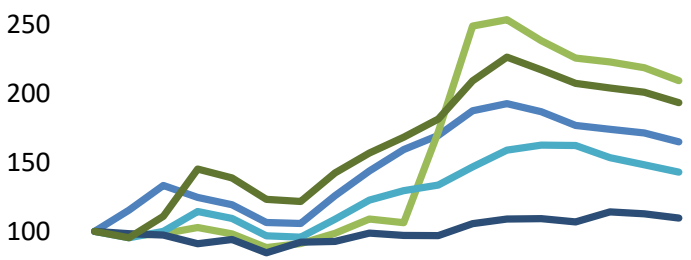

50

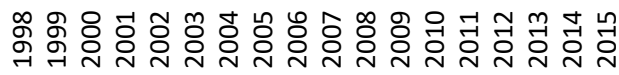

- AuditorP-f $\longrightarrow$ C\&T-m-f Defensor-f $\longrightarrow$ Docente-m-f $\quad$ Gestão-f

Fonte: Tabelas de remuneração dos servidores públicos. Elaborado pelos autores.

O Gráfico 2 apresenta as remunerações para as carreiras de auditores da previdência, defensores federais, cargos de gestão, docente e pesquisadores de C\&T com o título de mestrado. No Gráfico 2 (a) é possível observar que o nível salarial dos defensores, gestores e auditores é o maior, com destaque para os primeiros. A queda de salário no início do período é observada também, como no Gráfico 1, mostrado anteriormente. Quanto ao nível salarial de forma geral, é nítido que os docentes e pesquisadores possuem remunerações substancialmente menores do que as das demais carreiras. Observa-se que, quanto aos ganhos relativos, os gestores auferiram os maiores ganhos, seguidos pelos pesquisadores e docentes, isso também a partir do segundo mandato do Governo Lula. Essa valorização passa por queda a partir de 2011. A partir dos Gráficos 1 e 2, é possível perceber que a titulação não é um fator muito relevante para o nível salarial no setor público.

O Gráfico 2 (b) apresenta os salários finais, e a movimentação das remunerações é similar à evolução das remunerações iniciais. Isso com exceção de um pico salarial dos pesquisadores em C\&T em 2008, 
o que lhes garantiu uma variação relativa maior. Porém, como já mencionado, o nível de salário dessa carreira é significativamente menor, ou seja, em termos brutos as valorizações são menores e o nível salarial permanece abaixo. Todos os salários apresentam inicialmente um movimento ascendente, com tendência a aumentar e, a partir de 2010, a cair. Novamente, se vê o padrão de ascendência durante o Governo Lula e queda no de Dilma. A reposição do Governo Dilma, portanto, é sistematicamente abaixo da inflação.

O Gráfico 3 mostra as carreiras de advogado geral da União (Doravante AGU), especialistas do Inmetro ${ }^{12}$ com doutorado, analistas da Comissão de valores Mobiliários (CVM), especialistas do $\mathrm{IBGE}^{13}$ com doutorado e os oficiais de inteligência da Agência Brasileira de Inteligência (ABIN). Os servidores do IBGE e do Inmetro recebem suas remunerações compostas por vencimento básico mais a gratificação por atividades específicas de ambos os institutos, ${ }^{14}$ além de retribuição por titulação. Os advogados da União, a partir de 2006, passaram a receber via subsídio, acontece o mesmo com os servidores da CVM, a partir de 2008. Observando o Gráfico 3(a), percebe-se que os maiores salários são das carreiras de Estado, analistas da CVM, advogados da União e oficiais da Abin, e no início do período elas já apresentavam aumento de suas remunerações, o que é suavizado a partir de 2011. De forma relativa, os analistas da CVM e oficiais da ABIN receberam os maiores aumentos durante esse período, enquanto os analistas do Inmetro observaram menor valorização.

\section{GRÁFICO 3 EVOLUÇÃO DOS SALÁRIOS EM VALORES REAIS DE 2006 A 2015. INICIAIS (A) E FINAIS (B)}
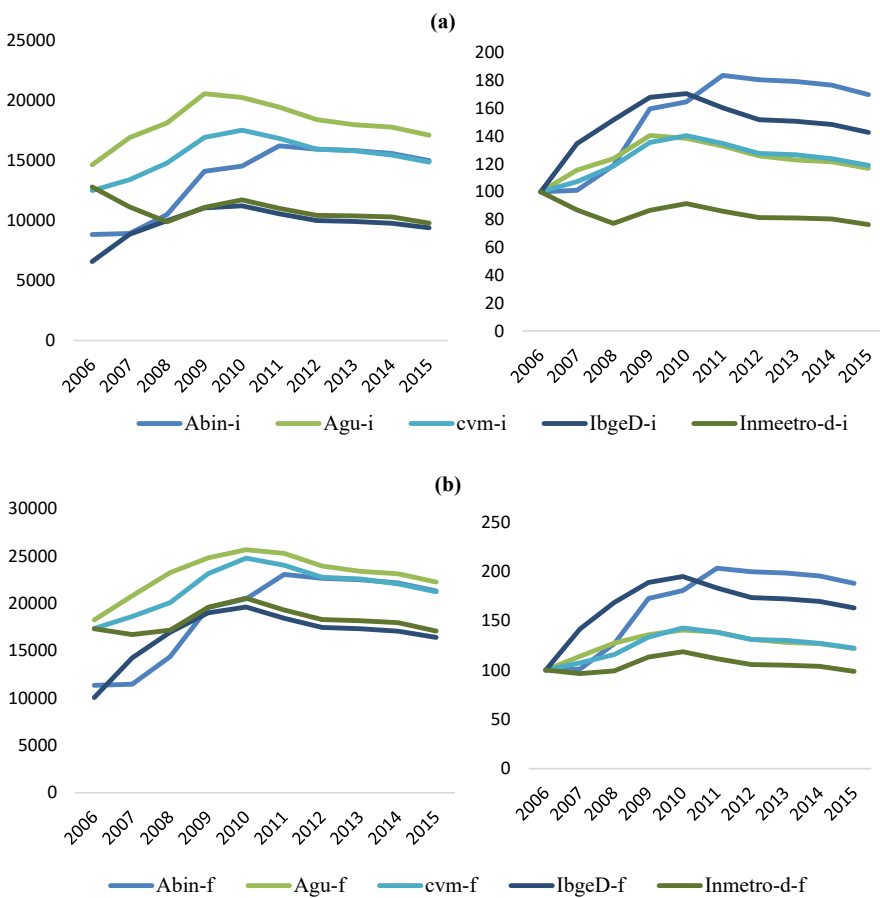

Fonte: Tabelas de remuneração dos servidores públicos. Elaborado pelos autores.

\footnotetext{
${ }^{12}$ Pesquisador-Tecnologista em Metrologia e Qualidade e Analista Executivo em Metrologia e Qualidade - Inmetro..

${ }^{13}$ Pesquisadores e tecnologistas do IBGE.

${ }^{14}$ A gratificação por desempenho pode variar de 80 a 100 pontos, de acordo com a produtividade do órgão como um todo, os primeiros 80 pontos, e o desempenho individual dos servidores, os outros 20 pontos. Em uma pesquisa realizada quanto à pontuação dos servidores nesses institutos, verifica-se que a grande maioria dos servidores recebem os 100 pontos. O que sugere que a parcela de remuneração que é atribuída ao desempenho não seja paga de forma eficiente.
} 
No que se refere aos tetos salariais (3b), verifica-se uma menor discrepância quanto ao nível de salários, se comparados aos gráficos anteriores entre as carreiras típicas de Estado e aquelas não típicas. Esses gráficos, por começarem em 2006, evidenciam de forma mais nítida a valorização geral ocorrida no segundo mandato do Governo Lula. Contudo, novamente, a partir de 2011, os salários caem em valores reais e se mantêm, sem ganhos a partir desse período.

O Gráfico 4 mostra os salários dos pesquisadores do Instituto Nacional de Estudos e Pesquisas Educacionais Anísio Teixeira (doravante pesquisadores do INEP), com doutorado, dos procuradores e delegados federais, dos especialistas das Agências Reguladoras (AR) e dos técnicos de planejamento e pesquisadores do Instituto de Pesquisa Econômica Aplicada (Ipea). Todas as carreiras apresentam tendência a aumento dos salários até 2010, quando os salários em valores reais começam a cair. $\mathrm{O}$ padrão Lula (aumento) e Dilma (queda) se repete. A carreira de delegado federal possui o maior salário em todos os períodos, seguida muito de perto pelos procuradores da Fazenda e pelos servidores do Ipea. A partir do Gráfico 4, é possível perceber que o salário dos pesquisadores doutores do INEP e das Agências reguladoras é substancialmente mais baixo do que os de outras carreiras, as quais são carreiras típicas de Estado.

\section{GRÁFICO 4 EVOLUÇÃO DOS SALÁRIOS EM VALORES REAIS DE 2006 A 2015. INICIAIS (A) E FINAIS (B)}
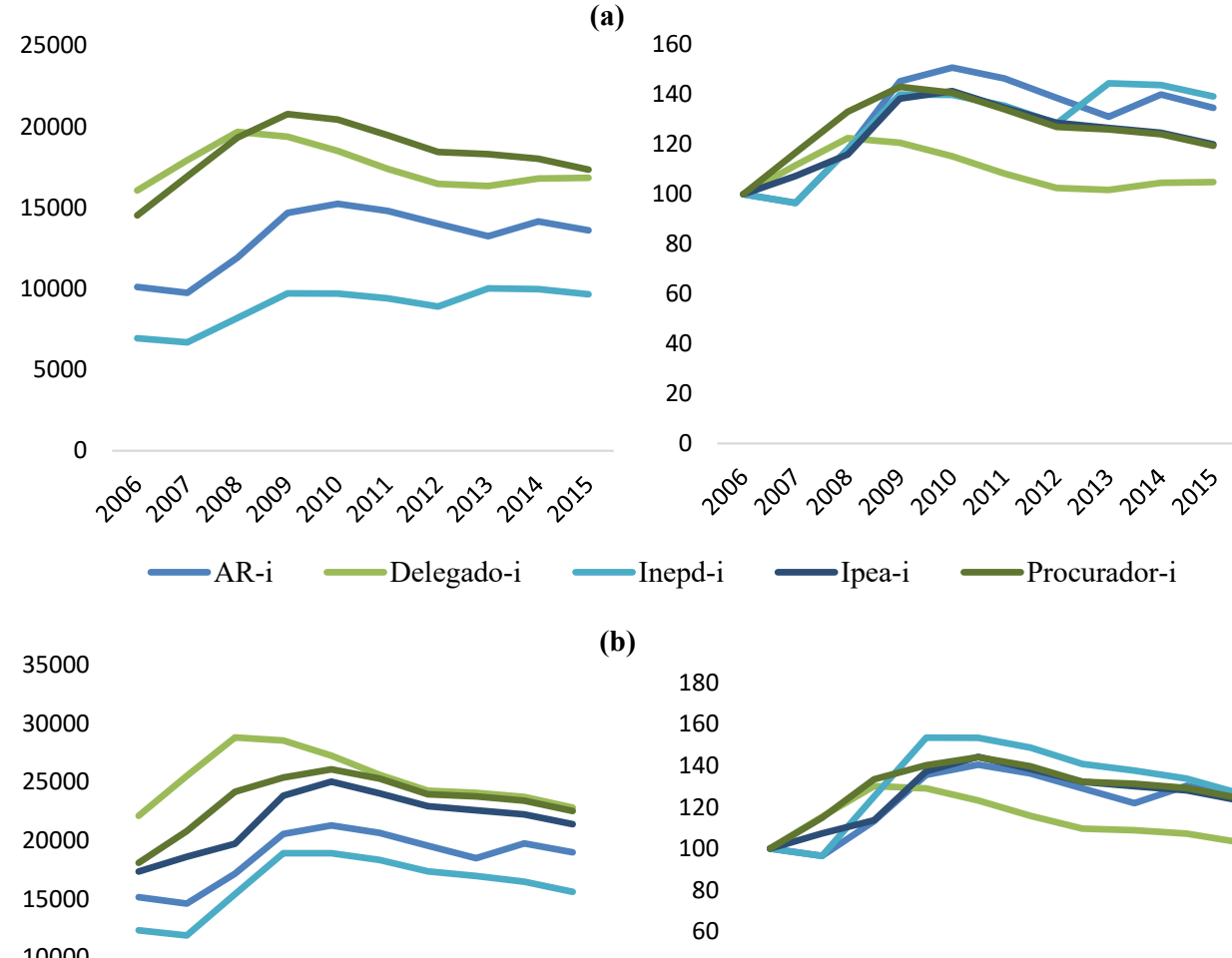

(b)

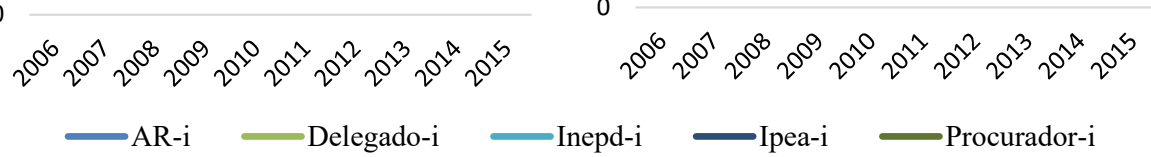

10000

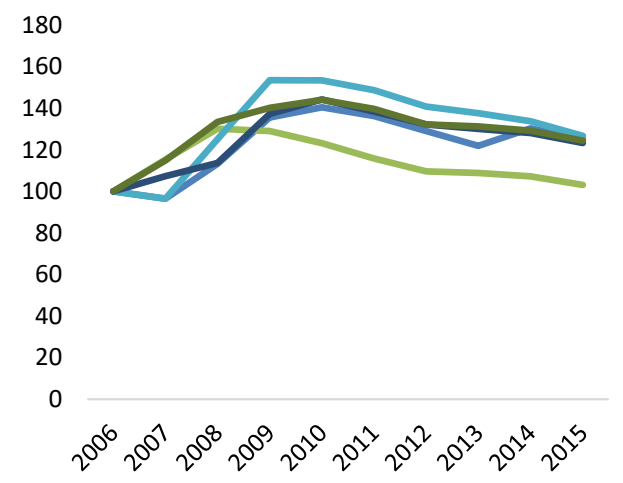

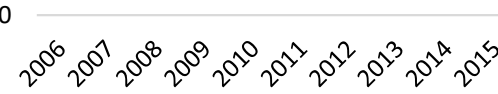

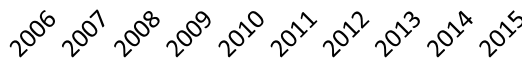

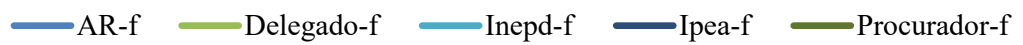

Fonte: Tabelas de remuneração dos servidores públicos. Elaborado pelos autores. 
Todas as carreiras apresentam tendência a aumento dos salários até 2010, quando os salários em valores reais começam a cair. O padrão Lula (aumento) e Dilma (queda) se repete. A carreira de delegado federal possui o maior salário em todos os períodos, seguida muito de perto pelos procuradores da Fazenda e pelos servidores do IPEA. A partir do Gráfico 4, é possível perceber que o salário dos pesquisadores doutores do INEP e das Agências Reguladoras é substancialmente mais baixo do que os de outras carreiras, as quais são carreiras típicas de Estado.

No que se refere à variação salarial no período como um todo, a carreira que mais observou aumento relativo foi a dos especialistas das agências reguladoras, o que mostra uma valorização sistemática dessa carreira no período citado. Os salários iniciais dessa carreira, portanto, se aproximam das remunerações das outras duas carreiras. Isso pode ser parte de uma política deliberada de atração, uma vez que os grandes aumentos se localizam especificamente nos anos de 2007 e 2008 . Ao mesmo tempo, isso pode ser resultado de uma reestruturação negociada, ${ }^{15}$ o que mostraria que os especialistas em regulação tiveram sucesso em tentar a equiparação de sua carreira - uma carreira de fiscalização - com as carreiras típicas de Estado. O que esses gráficos revelam, tanto para salários iniciais quanto finais, é a carreira de fiscalização e de um órgão de assessoramento muito próximo do Ministério do Planejamento (Ipea) - localização na estrutura do Estado e função - se sobrepõe novamente ao grau de escolaridade exigido, como o cargo do INEP e outros mostrados anteriormente.

A análise apresentada sugere que há sim uma grande valorização do funcionalismo no Governo Lula, enquanto o Governo Dilma deixou a inflação corroer as remunerações dos servidores. A exceção aqui é a remuneração final dos docentes - mas não a inicial -, que recebeu valorização durante todo o Governo de Dilma Rousseff. É necessário marcar que deixar as remunerações dos servidores serem corroídas pela inflação é a única maneira que o Governo tem para baixar esses salários, uma vez que a Constituição Federal prevê, em seu Art. 37, inciso XV, a irredutibilidade nominal dos vencimentos.

A partir do que foi o apresentado, é possível fazer algumas considerações preliminares. Foi possível perceber que as carreiras consideradas típicas de Estado possuem, em geral, níveis salariais mais elevados do que as não típicas, da mesma forma aquelas carreiras que possuem atividades ligadas de forma mais direta ao centro do Poder Executivo também possuem maiores níveis salariais - como a carreira do Ipea. Em muitos dos casos a variação ao longo do tempo dos salários relativos é maior para as carreiras não típicas. Contudo, vale ressaltar que os aumentos não são suficientes para que os salários dessas carreiras se aproximem daqueles associados às típicas, ainda que os reajustes concedidos sejam maiores. Isso ficará ainda mais claro na análise de clusters, a seguir.

Em termos da periodização, a reestruturação para remuneração por meio de subsídio parece ser decisiva para aumentos. É possível que ao mudar a remuneração para subsídio, parcelas que ficavam ocultas dos dados do Ministério do Planejamento tenham sido incorporadas às remunerações dos servidores. Além disso, temporalmente, poucas carreiras fugiram do padrão de queda-aumento-queda mais tênue que, grosso modo, correspondem aos Governos de FHC, Lula e Dilma. É claro que fatores relacionados à situação da economia nacional - crescimento/estagnação - e, por conseguinte, com a arrecadação, devem estar ligados à explicação desse padrão. Adicionalmente, inclinações ideológicas,

\footnotetext{
${ }^{15}$ Em julho de 2008 a carreira das agências reguladoras passou por uma reestruturação em conjunto com um reajuste salarial, através da Lei no 11.907 de 02.02.2009 (não foi encontrada a medida provisória anterior à lei). Essa lei retirou a vantagem pecuniária individual de tais servidores e foi instituído o sistema de pontos, por meio da Gratificação de Desempenho dos Planos Especiais de cargos das Agências Reguladoras.
} 
pretensões de eleição e reeleição e características diversas da chefia do Executivo e do primeiro escalão são importantes para explicar esse padrão. Várias hipóteses podem ser testadas e analisadas, talvez principalmente por estudos de caso particulares para as carreiras, a partir desses dados exploratórios.

Finalmente, as carreiras que possuem títulos como doutorado e mestrado, ainda que experimentem uma valorização no período, permanecem com níveis salariais bem abaixo de carreiras como a de advogados da União e procuradores federais. Vê-se, portanto, que o nível educacional, variável típica de explicação de salários no setor privado, não é decisiva para o caso do setor público.

Na próxima seção será apresentada a análise de agrupamento, sendo seu principal objetivo verificar como essas carreiras se comportaram no período de análise em termos de homogeneidade de remuneração para a formação dos grupos.

\section{MÉTODO: ANÁLISE DE AGRUPAMENTO}

A metodologia de análise de agrupamentos busca verificar, dado um determinado conjunto de observações, se existem características semelhantes entre as mesmas que possa as agrupar em um número finito de conjuntos, cada um deles não vazio. No caso do presente estudo, o intuito é verificar a existência de semelhança estatística entre as remunerações de diferentes carreiras do serviço público do e Executivo da União, considerando determinados períodos de tempo. O que se busca com tal metodologia de análise é a formação de grupos - ou clusters -, nos quais exista homogeneidade interna em relação à variável-escopo: a remuneração (Fávero \& Belfiore, 2015; Kaufman \& Rousseeuw, 1990).

Para que um cluster seja formado é necessário que as observações dentro de um mesmo grupo sejam relativamente - ao grupo de todas as observações - e estatisticamente semelhantes entre si e, ao mesmo tempo, diferentes das observações do outro cluster. Isso será feito para diferentes períodos, com o objetivo de mostrar se existe uma variação dos grupos ao longo do tempo. Vale dizer que a análise de agrupamento é um método diferente daqueles convencionalmente utilizados para classificação, uma vez que sua aplicação não requer que existam hipóteses prévias sobre a formação dos grupos. Ela não apresenta, portanto, um caráter preditivo para outras observações que não estão na amostra, representando, dessa forma, apenas uma técnica de análise exploratória e descritiva dos dados.

Assim como mencionado, a análise foi aplicada para diferentes períodos, utilizando a média das remunerações iniciais e finais deflacionadas para cada carreira, em cada período. A periodicidade escolhida para se fazer as diferentes análises de agrupamento foram os ciclos políticos coincidentes com os mandatos dos chefes do Executivo da União, isto é, o mandato dos presidentes: segundo mandato de Fernando Henrique Cardoso, primeiro e segundo mandatos de Luís Inácio Lula da Silva e primeiro mandato de Dilma Vana Rousseff. Embora muitas variáveis influenciem a formação das remunerações do setor público, é de se esperar que, principalmente em relação à valorização, manutenção ou desvalorização das carreiras, o mandatário do Poder Executivo tenha poder de decisão e o exerça, mudando os agrupamentos de carreiras mais e menos valorizadas. Além disso, foi aplicada uma análise de agrupamento para a média das remunerações finais e iniciais para todo o período (1998-2015).

Existem dois métodos para a análise de cluster, o método hierárquico permite que os dados se comportem de forma aleatória, o que torna possível a identificação de forma livre do ordenamento e alocação das observações (Fávero \& Belfiore, 2015). A partir desse método, promove-se uma estrutura hierárquica para a formação dos grupos. Inicialmente formam-se tantos grupos quanto o 
número de observações e em seguida os subgrupos vão se formando de acordo com as semelhanças das características. Dentro do método hierárquico é possível aplicar o método aglomerativo ou o divisível (Kaufman \& Rousseeuw, 1990).

O segundo método dito não hierárquico consiste na maximização de características semelhantes entre as observações dentro de um determinado grupo e preliminarmente é definida uma quantidade de clusters que se pretende formar. No presente trabalho inicialmente foi aplicado o método hierárquico para que fosse observado como os dados iriam se comportar, bem como a quantidade de clusters que seriam formados. Feita essa análise, o segundo momento consiste na aplicação do método não hierárquico, no qual a quantidade de clusters definida foi baseada no número de clusters formado a partir do primeiro método.

No que se refere à característica dos dados, existem dois métodos de análise possíveis. O primeiro, parte do estudo de comportamento de semelhança (medidas de similaridade), as quais são usadas quando as variáveis são binárias e o que importa é a frequência dos pares de resposta que convergem. O segundo método consiste em definir a distância (dissimilaridade), aplicado quando as variáveis são essencialmente métricas. Como no presente estudo as variáveis utilizadas para a formação dos clusters são os salários das diferentes categorias, aplicou-se esse último método de medidas de dissimilaridade. ${ }^{16}$

Na literatura existem alguns critérios de dissimilaridade para que as variáveis sejam agrupadas. Para efeitos dessa análise, foram testados todos e, ao fim, optou-se por apenas um deles para as variáveis métricas, a distância mais comum, dita Euclidiana, ela é a distância mais comum, medindo a distância geométrica entre duas observações de tamanho $n$, sejam $x=\left[x_{1}, x_{2}, \ldots . x_{n}\right]$ ey $=\left[y_{1}, y_{2}, \ldots . ., y_{n}\right]$ tem-se:

$$
d_{x y}=\sqrt{\sum_{i=1}^{p}(x i-y i)^{2}}
$$

O Quadro 1 a seguir mostra as carreiras e os respectivos clusters. A partir da análise gráfica através do método silhouette, é apresentado que o número ótimo de cluster é três. A carreira de delegado se mostra um pouco distante das demais carreiras do cluster 3 , o que faz sentido já que os salários dos delegados em termos reais são os maiores, e com o passar dos anos o salário perdeu poder de compra de forma significativa. Atualmente o salário se equipara ao das demais carreiras. Esse cluster é formado por quase totalmente carreiras típicas de Estado, com exceção da carreira das agências reguladoras. ${ }^{17}$ Além de não fazer parte das carreiras típicas, as remunerações das agências reguladoras não são pela forma de subsídio. A carreira de técnico de planejamento e pesquisa do Ipea também não é de Estado,

\footnotetext{
${ }^{16}$ Inicialmente foi feita uma análise de cluster em que considerou-se o quantitativo de servidores nas categorias, no entanto esse dado não é encontrado para a carreira de oficial da ABIN, e ao observar os clusters formados foi verificado que o peso dado para o quantitativo era elevado, não dando importância para os salários, que são o foco do estudo. Para incluir o quantitativo foi necessário realizar uma padronização dos dados. Após a aplicação da metodologia foram formados dois grupos, um que continha apenas a carreira de docente e outro com todas as demais carreiras. A explicação para tal fenômeno é que a carreira de docente possui um quantitativo de servidores muito elevado quando comparado com os demais, no entanto como pode ser visto posteriormente, o quantitativo no que se refere a determinação salarial e os reajustes pode não ser uma variável tão relevante, portanto, optou-se por retirá-lo da análise de agrupamento. ${ }^{17}$ Cabe ressaltar que a categorias das agências reguladoras recebem a GQ, gratificação por qualificação que é concedida àqueles servidores que possuem cursos oferecidos dentro do próprio órgão, essa gratificação poder ser concedida no valor de 10\% a 20\% do maior vencimento básico das categorias. A média salarial usada para a análise de agrupamento foi a dos servidores que recebem a GQ de $20 \%$.
} 
no entanto, recebe via subsídio e possui uma média salarial parecida com as carreiras típicas, as quais também recebem via subsídio.

\section{QUADRO 1 ANÁLISE DE CLUSTER (1998-2015)}

$\begin{array}{ccc}\text { Cluster } 1 & \text { Cluster } 2 & \text { Cluster 3 } \\ \text { Inmetro - Doutorado } & \text { C\&T } & \text { Advogado da União } \\ \text { IBGE - Mestrado } & \text { Docente - Mestrado } & \text { Procurador Federal } \\ \text { C\&T - Doutorado } & \text { D\&T - Mestrado } & \text { Defensor Federal } \\ \text { Agente da Polícia Federal } & \text { Docente - Graduação } & \text { Procurador da Fazenda } \\ \text { Inmetro - Mestrado } & \text { Auditor da Receita } \\ \text { IBGE - Especialização } & \text { Docente - Aperfeiçoamento } & \text { Auditor da Previdência } \\ \text { INEP - Especialização } & \text { Docente - Especialização } & \text { Analista do Bacen } \\ \text { INEP - Mestrado } & & \text { Agência Reguladora } \\ \text { Docente - Doutorado } & \text { Gestor } \\ \text { Ipea } & & \text { Téc. Pesquisa Ipea } \\ \text { INEP - Doutorado } & \text { CVM } \\ \text { IBGE - Doutorado } & \text { Diplomata } \\ & & \text { Delegado Federal } \\ & & \text { ABIN }\end{array}$

Fonte: Dados processados no software R. Elaborado pelos autores.

O Quadro 2 abaixo mostra a média dos salários iniciais e finais para cada cluster. É possível perceber que o cluster 2 possui as menores médias e a diferença para os demais é substancial, nesse grupo estão as carreiras de docente, exceto aquela com retribuição por título de doutor, e o os pesquisadores de ciência e tecnologia. O cluster 1 agrupa as carreiras ligadas aos institutos de pesquisa como o INEP e IBGE e as carreiras de docente e ciência e tecnologia com título de doutor. Cabe notar que nos institutos de pesquisa (exceto o Ipea) existe a retribuição pela titulação e mesmo com esse adicional os salários são menores do que os das carreiras típicas, pertencentes ao cluster 3.

\section{QUADRO 2 MÉDIAS SALARIAIS (1998-2015)}

\begin{tabular}{|c|c|c|}
\hline Cluster & Salário Inicial & Salário Final \\
\hline 1 & $8.797,38$ & $14.543,42$ \\
\hline 2 & $4.847,84$ & $8.013,00$ \\
\hline 3 & $13.883,28$ & $19.155,77$ \\
\hline
\end{tabular}

Fonte: Dados processados no software R. Elaborado pelos autores. 
Como a amostra possui os salários por um período de 17 anos, foi utilizada a média para o período como um todo. Achou-se conveniente, também, fazer a análise separando os dados por ciclo político. A justificativa para tal é que, nos últimos anos de cada ciclo, o setor executivo passa por uma recomposição de servidores e de salários. Além disso, durante o período estudado, o Executivo foi comandado por três mandatos presidenciais distintos, com agendas e inclinações políticas diferentes. Portanto, as relações e os contextos políticos podem ter sido transferidos para as relações salariais no setor público. ${ }^{18}$ Dessa maneira, a análise objetiva verificar se o comportamento dos salários e o agrupamento das categorias são distintos durante os diferentes ciclos políticos ou se o padrão permanece sempre o mesmo.

Durante o primeiro ciclo político ocorreu a Reforma Gerencial da administração pública. Ao aplicar o método não hierárquico verifica-se que 3 é um número ideal de clusters. O que se percebe é que a carreira de delegado fica muito distante das demais, dessa forma entende-se que três grupos é uma formação conveniente. A partir dessa formulação é possível notar que as carreiras típicas de Estado formam um único grupo, com exceção da de delegado que fica em um grupo isolado, as carreiras ligadas a pesquisa e docência formam também, por sua vez, um único grupo. Inclusive aquelas com maiores titulações. A justificativa para tal é que nesse período ainda não havia ocorrido a política de valorização do título de doutorado e, portanto, carreiras que previam a remuneração por titulação ainda não tinham salários com maiores níveis.

O Quadro 3 mostra as carreiras e os respectivos grupos os quais cada carreira pertence ${ }^{19}$.

\section{QUADRO 3 ANÁLISE DE CLUSTER: CICLO POLÍTICO 1 (1998-2002)}

\begin{tabular}{|c|c|c|}
\hline Cluster 1 & Cluster 2 & Cluster 3 \\
\hline $\begin{array}{c}\text { C\&T - Doutorado } \\
\text { C\&T } \\
\text { Docente - Mestrado } \\
\text { C\&T - Mestrado } \\
\text { Docente - Graduação } \\
\text { Docente - Aperfeiçoamento } \\
\text { Docente - Especialização } \\
\text { Docente - Doutorado }\end{array}$ & Delegado & $\begin{array}{l}\text { Advogado da União } \\
\text { Procurador Federal } \\
\text { Defensor Federal } \\
\text { Procurador da Fazenda } \\
\text { Auditor da Receita } \\
\text { Auditor da Previdência } \\
\text { Analista do Bacen } \\
\text { Agência Reguladora } \\
\text { Gestor } \\
\text { Téc. Pesquisa Ipea } \\
\text { CVM } \\
\text { Diplomata } \\
\text { Delegado Federal }\end{array}$ \\
\hline
\end{tabular}

Fonte: Dados processados no software R. Elaborado pelos autores.

\footnotetext{
${ }^{18}$ Para uma análise mais profunda ver Ventura (2018).

${ }^{19}$ Cabe ressaltar que no primeiro ciclo político (1998-2002) não existiam todas as remunerações para todas as carreiras. Nesse caso a análise foi feita para 22 carreiras diferentes, apenas.
} 
A seguir, a o Quadro 4 mostra as médias salariais de cada grupo.

\section{QUADRO 4 MÉDIAS SALARIAIS: CICLO POLÍTICO 1}

\begin{tabular}{ccc} 
Cluster & Salário Inicial & Salário Final \\
\hline 1 & $3.978,40$ & $6.959,40$ \\
2 & $8.425,72$ & $13.483,90$ \\
3 & $12.044,05$ & $17.039,98$ \\
\hline
\end{tabular}

Fonte: Dados processados no software R. Elaborado pelos autores.

O comportamento da formação de grupos não se mostra muito diferente do ciclo político 1 . No entanto, para tal período mais categorias foram incorporadas na análise. Ao fazer a análise não hierárquica, o melhor resultado para o agrupamento é de 4 grupos. A carreira de delegado não aparece mais sozinha, fazendo parte de um grupo com outras carreiras típicas de Estado, as quais possuem a maior média de salários. O cluster 2, é formado por carreiras típicas de Estado mais as carreiras do Ipea. O cluster 3 é formado pelas carreiras do IBGE, INEP, Abin e pesquisador de C\&T. Por fim, o cluster 4 é formado pelas carreiras de docente, institutos de pesquisa e pesquisadores, com a menor média de salários. O Quadro 5 mostra a as carreiras e seus respectivos clusterclusters.

\section{QUADRO 5 ANÁLISE DE CLUSTER: CICLO POLÍTICO 2 (2003-2006)}

\begin{tabular}{cccc}
\hline Cluster $\mathbf{1}$ & Cluster 2 & Cluster 3 & Cluster 4 \\
\hline ABIN & IBGE - Mestrado & Advogado da União & Procurador da Fazenda \\
IBGE - Mestrado & C\&T - Mestrado & Ipea & Auditor da Receita \\
IBGE - Doutorado & C\&T & Defensor Federal & Auditor da Previdência \\
Docente - Doutorado & INEP - Mestrado & Agência Reguladora & Delegado da Polícia Federal \\
Agente da Polícia Federal & INEP - Especialização & Gestor & Inmetro - Doutorado \\
C\&T - Doutorado & Docente - Especialização & Téc. Pesquisa Ipea & Analista do Bacen \\
IBGE - Doutorado & Docente - Graduação & CVM & Inmetro - Doutorado \\
IBGE - Especialização & Docente - Aperfeiçoamento & Diplomata & Procurador Federal \\
\hline
\end{tabular}

Fonte: Dados processados no software R. Elaborado pelos autores.

O Quadro 6 apresenta as médias salariais de cada grupo. É possível notar que o cluster 4 possui as maiores médias e, por sua vez, é composto essencialmente por carreiras típicas. A diferença para o 
cluster 2, com menor média, é substancial e este é composto pelos institutos de pesquisa e docência, carreiras as quais recebem pela titulação. Nesse grupo estão contidas as remunerações que englobam as retribuições pelo título de mestre, por exemplo. É bom lembrar que as carreiras típicas recebem, atualmente, via subsídio, o que significa o recebimento de apenas uma parcela remuneratória. No período do segundo ciclo político, a remuneração não consistia em parcela única e, adicionalmente, não havia retribuição por titulações adicionais. Essa mudança indica uma valorização da carreira por si mesma e pouca valorização da formação acadêmica.

QUADRO 6 MÉDIAS SALARIAIS: CICLO POLÍTICO 2 (2003-2006)

\begin{tabular}{ccc} 
Cluster & Salário Inicial & Salário Final \\
\hline 1 & $7.130,40$ & $11.026,92$ \\
\hline 2 & $4.560,83$ & $7.399,42$ \\
\hline 3 & $10.025,16$ & $14.473,72$ \\
\hline 4 & $12.639,74$ & $16.871,60$ \\
\hline
\end{tabular}

Fonte: Dados processados no software R. Elaborado pelos autores.

O Quadro 7 apresenta os resultados do agrupamento e faz um mapeamento dos grupos aos quais cada uma das categorias fazem parte para o ciclo político 3, que representa o período do segundo Governo Lula (2007-2011). As categorias de servidores públicos formam novamente quatro grupos de acordo com a média dos salários nesse período. Nesse ciclo a formação dos clusters se mostra um pouco diferente dos anteriores, as carreiras típicas formam dois grupos com as maiores médias salariais, os clusters 1 e 2 . Apenas a carreira de defensor público da União que é típica que não está em nenhum desses grupos, pertencendo ao cluster 3 , formado em grande parte por carreiras ligadas a área de pesquisa e educação, com algum nível de titulação. Novamente, o método aglomerativo se mostrou melhor do que o divisível nessa primeira análise.

A partir da formação de grupos pelo método hierárquico, é feita a análise não hierárquica. Pela análise da silhouette, verifica-se que o agrupamento em 4 clusters é o mais adequado, que mantém o agrupamento do método hierárquico. O cluster 3 apresenta a terceira maior média, com carreiras do IBGE, Inmetro, docente com doutorado, pesquisador de C\&T com doutorado, defensor e agente da Polícia federal. Analisando em conjunto com as análises de agrupamento apresentadas anteriormente, é possível perceber que as categorias ligadas ao Inmetro e IBGE são mais valorizadas do que as do INEP e a carreira de docente com menores níveis de titulação. 
QUADRO 7 ANÁLISE DE CLUSTER: CICLO POLÍTICO 3 (2007-2010)

$\begin{array}{cccc}\text { Cluster } 1 & \text { Cluster } 2 & \text { Cluster } 3 & \text { Cluster 4 } \\ \text { Advogado } & \text { ABIN } & \text { Agente } & \text { INEP - Mestrado } \\ \text { Delegado } & \text { Analista Bacen } & \text { C\&T - Doutorado } & \text { INEP - Especialização } \\ \text { Auditor da Receita } & \text { Agência Reguladora } & \text { Defensor } & \text { Docente - Mestrado } \\ \text { Auditor da Previdência } & \text { Téc. Pesq. Ipea } & \text { Docente - Doutorado } & \text { Docente - Graduação } \\ \text { Procurador Federal } & \text { Ipea } & \text { IBGE - Doutorado } & \text { Docente - Especialização } \\ & \text { Diplomata } & \text { IBGE - Especialização } & \text { C\&T - Mestrado } \\ & \text { Analista da CVM } & \text { IBGE - Mestrado } & \text { Docente - Aperfeiçoamento } \\ & \text { Procurador da Fazenda } & \text { INEP - Doutorado } & \text { C\&T } \\ & \text { Gestão } & \text { Inmetro - Doutorado } & \end{array}$

Fonte: Dados processados no software R. Elaborado pelos autores.

O Quadro 8 mostra as médias salariais de cada cluster, é possível perceber que os clusterclusters 1 e 2 possuem as maiores médias salariais, compostos pelas carreiras típicas de Estado. Nesse sentido, nota-se que esse padrão é mantido ao longo do tempo. Essas carreiras possuem os maiores salários, mesmo que ao longo do tempo tenha ocorrido recomposições salariais para as carreiras de forma geral. Portanto, esse aumento não foi o suficiente para equiparar os salários, mesmo considerando carreiras que requerem níveis adicionais de escolaridade.

\section{QUADRO 8 MÉDIAS SALARIAIS: CICLO POLÍTICO 3 (2007-2010)}

\begin{tabular}{ccc} 
Cluster & Salário Inicial & Salário Final \\
\hline 1 & $18.771,31$ & $25.244,14$ \\
\hline 2 & $15.353,35$ & $21.091,70$ \\
\hline 3 & $9.987,20$ & $16.094,74$ \\
4 & $5.861,74$ & $9.765,45$ \\
\hline
\end{tabular}

Fonte: Dados processados no software R. Elaborado pelos autores. 
Por fim, é feita a análise para o último ciclo político, referente ao primeiro mandato da presidenta Dilma Roussef (2011-2015). Nesse último ciclo é possível verificar que as carreiras típicas de Estado convergem formando um único grupo. Assim, ao longo dos ciclos essas carreiras ainda que não tenham sido as mais valorizadas, ${ }^{20}$ continuaram com as maiores médias salariais. Mostrando, desse modo, que essas carreiras possuem salários sempre mais elevados que as demais categorias, indicando uma valorização dessas funções quando comparadas com as outras. A partir da análise não hierárquica verifica-se que o melhor agrupamento é com a formação de 3 grupos.

O Quadro 9 mostra as carreiras e seus respectivos clusters, ao observar a primeira análise de agrupamento nota-se que a formação dos grupos é a mesma. No Quadro 9, percebe-se também que houve uma queda das médias salariais, a justificativa para tal é que no mandato da presidenta Dilma, em função da crise econômica não ocorreu uma recomposição dos salários de forma a manter o poder de compra, dada a inflação. Ainda, no ano de 2015 a inflação brasileira se mostrou acima dos anos anteriores, chegando a $10,67 \%$.

\section{QUADRO 9 ANÁLISE DE CLUSTERS: CICLO POLÍTICO 4 (2011-2015)}

\begin{tabular}{ccc} 
Cluster 1 & Cluster 2 & Cluster 3 \\
\hline Inmetro - Doutorado & C\&T & Advogado da União \\
IBGE - Mestrado & Docente - Mestrado & Procurador Federal \\
C\&T - Doutorado & C\&T - Mestrado & Defensor Federal \\
Agente da Polícia Federal & Docente - Graduação & Procurador da Fazenda \\
Inmetro - Mestrado & Docente - Aperfeiçoamento & Auditor da Receita \\
IBGE - Especialização & Docente - Especialização & Auditor da Previdência \\
INEP - Especialização & & Analista do Bacen \\
INEP - Mestrado & Agência Reguladora \\
Docente - Doutorado & Gestor \\
Ipea & & Téc. Pesquisa Ipea \\
INEP - Doutorado & CVM \\
IBGE - Doutorado & Diplomata \\
& & Delegado Federal \\
& & ABIN
\end{tabular}

Fonte: Dados processados no software R. Elaborado pelos autores.

\footnotetext{
${ }^{20} \mathrm{Na}$ seção anterior quando foram apresentados os gráficos comparando as carreiras é possível observar esse fato.
} 
QUADRO 10 MÉDIAS SALARIAIS. CICLO POLÍTICO 4 (2011-2015)

\begin{tabular}{|c|c|c|}
\hline Cluster & Salário inicial & Salário final \\
\hline 1 & $8.791,377$ & $14.543,42$ \\
\hline 2 & $4.847,84$ & $8.013,00$ \\
\hline 3 & $13.883,271$ & $19.155,77$ \\
\hline
\end{tabular}

Fonte: Dados processados no software R. Elaborado pelos autores.

Após realizada a análise de agrupamento para o período todo (1998-2015) e, de forma separada, por ciclos políticos, é possível fazer algumas considerações. Durantes os períodos é perceptível que as carreiras típicas de Estado possuem maiores médias salariais do que as demais categorias, indicando, portanto, como já dito em seções anteriores, que essas carreiras possivelmente possuem maior poder de barganha no que se refere à determinação dos níveis salariais e também da recomposição salarial ao longo do tempo (Ventura, 2018).

Quando se compara as carreiras típicas de Estado com aquelas ligadas a pesquisa e educação, verifica-se em algum nível a valorização das primeiras e pouca valorização do nível educacional em detrimento da atividade exercida em si (função). Para a carreira dos docentes, cabe destacar que aqueles com o título de doutorado pertencem a um cluster separado, indicando a valorização dessa categoria de forma diferenciada em relação à categoria como um todo. No entanto, ainda que seja necessária a titulação de doutorado, o nível salarial dessa categoria está abaixo das carreiras típicas e de outras que, mesmo não sendo típicas, como a do Ipea e das agências reguladoras, possuem um maior nível salarial.

\section{CONCLUSÕES}

Neste trabalho buscou-se mostrar que existe dentro do Poder Executivo Federal uma segmentação nos salários no que se refere às diversas atividades exercidas dentro da Administração Pública. É possível observar a valorização de algumas funções em detrimento de outras, o que confere maiores benefícios, na forma de salários, para algumas categorias particulares. Esse conflito distributivo, em teoria, pode ser visto como motivado por duas razões. Primeiro, porque existem relações políticas distributivas dentro do próprio Poder Executivo. Segundo essas relações precisam se haver com a limitação dos recursos estatais, mais especificamente com a arrecadação. Disso, advém um processo de barganha intra-governamental. Nesse processo, então, os resultados encontrados podem apontar na direção de que algumas categorias possuem maior poder de barganha perante o governo. Obviamente, aqui estudaram-se os padrões relativos e os conjuntos da evolução das remunerações. Conclusões mais particulares e a análise, talvez com estudos de caso, dos poderes de barganha devem ser transbordamentos possíveis a partir do estudo apresentado.

Algumas conclusões são possíveis a partir da análise, além, é claro, dos resultados acerca da existência de grupos remuneratórios que se formaram ao longo do tempo e do padrão geral de quedaaumento-queda, observado ao longo dos Governos FHC, Lula e Dilma, respectivamente. 
A partir dos gráficos da seção 2, verifica-se que as carreiras consideradas típicas de Estado possuem níveis salariais mais elevados. No que se refere à reposição da inflação, em geral, observa-se que a variação salarial, ou seja, os ganhos salariais das carreiras não típicas foram maiores que o das outras carreiras. Porém, o nível salarial das categorias típicas de Estado apresenta-se sempre mais elevado.

Outra conclusão interessante é que, com base na análise dos gráficos, percebe-se que categorias como as de pesquisadores e docentes, que requerem títulos adicionais além da graduação em nível superior, não possuem os maiores salários. Portanto, é nítido que, para o caso específico brasileiro, os salários não possuem uma regra clara de determinação em função do nível educacional. Acredita-se ser necessária uma investigação adicional para analisar o poder de barganha dessas categorias.

A partir da análise de clusters, as tendências apresentadas pelos gráficos, são corroboradas. Verifica-se que as carreiras ligadas à área de gestão, que estão mais próximas do centro de decisão e, de forma geral, são consideradas carreiras típicas de Estado, se agrupam nos mesmos clusters. Isso ocorre tanto na análise do período como um todo, quanto nos ciclos políticos. Da mesma forma, percebe-se que, essas carreiras possuem os maiores salários, e as diferenças entre elas e os grupos chega a mais de $70 \%$. Nesse sentido, para o caso brasileiro existe um padrão muito claro de valorização dessas atividades que são essenciais para o funcionamento do Estado, como por exemplo, os auditores da Receita Federal e, de forma relativa, pouca valorização de carreiras com maiores titulações.

Esse trabalho deve suscitar novas pesquisas. Acredita-se, principalmente, que a partir desses dados gerais e do banco de dados formado, é possível investigar a evolução histórica das negociações das diversas categorias com o Executivo Federal. Por exemplo, carreiras pertencentes às áreas de ciência e tecnologia, saúde, educação aparentemente possuem remunerações sistematicamente abaixo de carreiras com as de fiscalização. Assim sendo, este trabalho estabelece alguns marcos gerais, usando uma metodologia da qual não se tem notícia de ter sido aplicada anteriormente ao caso, para que essa importante pesquisa concernente às remunerações do setor público possa avançar a partir da identificação dos padrões apresentados. 


\section{REFERÊNCIAS}

Barbosa, A. L. N. H., \& Souza, P. H. G. F. (2012). Diferencial salarial público-privado e desigualdade dos rendimentos do trabalho no Brasil. Brasília, DF: Instituto de Pesquisa Econômica Aplicada. Recuperado de http://repositorio.ipea.gov.br/ handle/11058/3854

Borjas, G. J. (1980). Wage determination in the federal government: The role of constituents and bureaucrats. Journal of Political Economy, 88(6), 1110-1147.

Braite, F. M. (2017). Impacto do crescimento econômico na desigualdade de renda: estudo para o caso brasileiro (Tese de Mestrado). Fundação Getulio Vargas, São Paulo, SP. Recuperado de http://hdl. handle.net/10438/17958

Bresser-Pereira, L. C. (1972). A emergência da tecnoburocracia. In B. Pereira (Ed.), Tecnoburocracia e Contestação. Rio de Janeiro, RJ: Editora Vozes.

Bresser-Pereira, L. C. (1981). Classes e Estratos sociais no Capitalismo Contemporâneo (Textos para Discussão, 117). Recuperado de http://hdl.handle. net/10438/1965

Bresser-Pereira, L. C. (2007). Burocracia pública na construção do Brasil. Revista de Sociologia e Política, 28, 9-30.

Bugarin, M., \& Souza, I. B. G. (2005). Negociação salarial dos servidores públicos federais: uma análise sob a ótica de economia política positiva. In Anais do $23^{\circ}$ Encontro Nacional de Economia, Natal, RN.

Cavalieri, M. (2016). Inside Institutions of ProgressiveEra Social Sciences: The Interdisciplinarity of Economics and Sociology. Journal of Economic Issues, 50(2), 345-361.

Constituição da República Federativa do Brasil. (1988). Brasília, DF: Senado Federal, Centro Gráfico.

Douglas, W., Araújo, E. R., \& Chaves, A. L. M. (2014). Omissão Inconstitucional e Revisão Anual Geral do Servidores Públicos: razões pelas quais o STF deve dar cumprimento ao Art. 37, X da Constituição. Niterói, RJ: Impetus.

Ehrenberg, R. G. (1973). The demand for state and local government employees. The American Economic Review, 63(3), 366-379.
Fávero, L., \& Belfiore, P. (2015). Análise de dados: técnicas multivariadas exploratórias com SPSS e STATA. São Paulo, SP: Campus/Elsevier.

Gregory, R. G., \& Borland, J. (1999). Recent developments in public sector labor markets. Handbook of labor economics, 3, 3573-3630.

Kaufman, L. \& Rousseeuw, P. J. (1990). Finding groups in data: an introduction to cluster analysis. Hoboken, NJ: John Wiley \& Sons.

Marconi, N. (2001). A formação dos salários nos setores público e privado (Tese de Doutorado). Fundação Getulio Vargas, São Paulo, SP. Recuperado de http://bibliotecadigital.fgv.br/dspace;/bitstream/ handle/10438/4640/1200101429.pdf

Marconi, N. (2014). A evolução do perfil da força de trabalho e das remunerações nos setores público e privado ao longo da década de 1990. Revista do Serviço Público, 54(1), 10-45.

Martins, L. (1997). Reforma da administração pública e cultura política no Brasil: uma visão geral (Cadernos ENAP). Brasília, DF: ENAP.

Ministério do Planejamento, Orçamento e Gestão. (2003). Gestão Pública para um Brasil de todos: um plano de gestão para o governo Lula. Brasília, DF: Autor.

Ministério do Planejamento, Orçamento e Gestão. (2015). Tabelas de remuneração dos servidores públicos federais. Brasília, DF: Autor.

Ministério do Planejamento Orçamento e Gestão. (2016). Boletim estatístico de pessoal, 21(248). Brasília, DF: Autor.

Moriconi, G. M. (2007). Todos os servidores públicos são bem remunerados? Uma comparação entre as carreiras dos governos estaduais brasileiros. In Anais do $35^{\circ}$ Encontro Nacional de Economia, Recife, PE. Recuperado de https://ideas.repec.org/p/anp/ en2007/049.html

Moriconi, G. M., Moura, J. S., Neto, Marconi, N., \& Arvate, P. R. (2009). Diferentes padrões de políticas salariais nos estados brasileiros: uma análise a partir do diferencial de salários público-privado. Brazilian Journal of Political Economy, 29(3), 114-134.

Niskanen, W. A. (1971). Bureaucracy and representative government. New Brunswick, NJ: Aldine Transaction. 
Souza, I. B. G. (2005). Negociação salarial dos servidores públicos federais: uma análise sob a ótica da economia política positiva. In Anais do $33^{\circ}$ Encontro Nacional de Economia, Porto Alegre, RS. Recuperado de https://ideas.repec.org/p/anp/ en2005/054.html

Souza, P. H. G. F., \& Medeiros, M. (2013). Diferencial salarial público-privado e desigualdade de renda per capita no Brasil. Estudos Econômicos, 43(1), 5-28.

Summers, C. W. (1974). Public employee bargaining: A political perspective. The Yale Law Journal, 83(6), 1156-1200.

Vaz, D. V., \& Hoffmann, R. (2007). Remuneração nos serviços no Brasil: o contraste entre funcionários públicos e privados. Economia e Sociedade, 16(2), 199-232.

Ventura, O. (2017, março). Hierarquia valorativa e distribuição de capitais na burocracia brasileira. Newsletter. Observatório de elites politicas e sociais do brasil, 4(2), 1-18.

Ventura, T. (2018). Conflito distributivo no setor público: uma análise da heterogeneidade salarial e dos determinantes de salários do Poder Executivo Federal através do poder de barganha (Dissertação de Mestrado). Universidade Federal do Paraná, Curitiba, PR.

Wellington, H. H., \& Winter, R. K. (1969). The limits of collective bargaining in public employment. The Yale Law Journal, 78(7), 1107-1127.

\section{Tailiny Ventura}

https://orcid.org/0000-0002-5657-798X

Doutoranda pelo Centro de Desenvolvimento e Planejamento Regional da Universidade Federal de Minas Gerais (UFMG); Bolsista Capes. E-mail: tailinyventura@gmail.com

\section{Marco Antonio Ribas Cavalieri}

https://orcid.org/0000-0002-4251-6879

Professor Associado da Pós-Graduação em Desenvolvimento Econômico e da Pós-graduação em Ciência Política da Universidade Federal do Paraná (UFPR).E-mail: cavaga@uol.com.br 